\title{
What is the Evidence for Endoscopic Thyroidectomy in the Management of Benign Thyroid Disease?
}

\author{
E. Th. Slotema $\cdot$ F. Sebag $\cdot$ J. F. Henry
}

Published online: 8 March 2008

(C) The Author(s) 2008

\begin{abstract}
Background Endoscopic thyroidectomy (ET) is a demanding surgical technique in which dissection of the gland is entirely performed with an endoscope, in a closed area maintained by insufflation or mechanical retraction. ET by direct cervical approach (anterior or lateral) is minimally invasive, but ET using an extracervical access (chest wall, breast, or axillary) is not. No technique seems to be universally accepted yet. This review was designed to clarify the existing evidence for performing endoscopic thyroid resections in the management of benign thyroid nodules.

Methods A database search was conducted in PubMed and Embase from which summaries and abstracts were screened for relevant data, matching our definition. Publications were further assessed and assigned their respective levels of evidence. Additional data derived from our own unit's experience with endoscopic thyroidectomy were included.

Results Thirty mainly retrospective cohort studies have been published in which morbidity, such as unilateral vocal cord palsy, is poorly evaluated. ET takes from 90 to 280 minutes for lobectomy by cervical access and total thyroidectomy by chest wall approach, respectively. Cosmetic outcome in extracervical approach is less troubled by size of the resected specimen compared with direct cervical approach. Extracervical approach avoids a neck scar but implies invasiveness in terms of dissection and
\end{abstract}

E. Th. Slotema $(\varangle) \cdot$ F. Sebag · J. F. Henry

Department of Endocrine Surgery University Hospital Marseille, Service de Chirurgie Générale et Endocrinienne, CHU-Hôpital de la Timone, 264 Rue Saint-Pierre, 13385 Marseille cedex 05, France

e-mail: e.t.slotema@lumc.nl postoperative discomfort. Long-term cosmetic outcome comparisons with conventional thyroidectomy have not been published.

Conclusions Currently it is not possible to recommend the application of ET based on evidence. Reported complications stress the importance of advanced endoscopic skills. ET should only be offered to carefully selected patients and, therefore, a high volume of patients requiring thyroid surgery is needed. Superiority of endoscopic to conventional thyroidectomy has yet to be demonstrated. Possible advantages of endoscopic thyroid techniques and our patient's desire for the highest cosmetic outcome possible justify further development of ET in expert hands of endocrine surgeons.

\section{Introduction}

Since its introduction in 1996, endoscopic thyroidectomy (ET) has yet to become a standard procedure. From the start, technical issues slowed down widespread application, and ET still is a demanding and technically challenging procedure. Certainly surgeons hesitate to implement a new technique as long as the "cost/benefit" ratio remains questionable.

No clear definition exists for ET. During the last 10 years, the use of an endoscope has been reported in several techniques of thyroidectomy. In some of these techniques, the endoscope is used during just one step of the procedure. Other steps are performed as in open techniques, by direct vision, through a mini-cervical incision. Video-assisted thyroidectomy may be a more appropriate name for these semi-open techniques. We defined ET as a surgical technique in which dissection of the gland is 
entirely performed with the help of an endoscope, in a closed area maintained by insufflation or mechanical retraction [1]. Semi-open procedures or partially endoscopic procedures, e.g. the video-assisted cervical approach, are consequently not evaluated in this article.

ET techniques can be subdivided into cervical or direct approaches and extracervical or indirect approaches. Generally endoscopic techniques are introduced because of their minimal invasiveness, expected to result in quicker convalescence and better cosmesis compared with traditional Kocher cervicotomy. ET by direct cervical approach is definitely minimally invasive; however, this is not true for other ET using an extracervical access. In these techniques, skin incisions for trocars and extraction of the specimen are made away from the neck, avoiding any scars in the neck, but widely extending the dissection area. To evaluate its current position, we have performed a review of published data on ET.

\section{Materials and methods}

A database search was conducted in PubMed and Embase (132 hits) using (Mesh-) terms "Endoscopy AND Thyroid Gland" (90 hits) "Endoscopy AND thyroid nodule/surgery" (15 hits) "laparoscopic thyroid surgery" (13 hits), without language restrictions. Summaries and abstracts of each identified publication were screened for relevant data on ET in humans. Only publications that fulfilled the inclusion criteria were further assessed and assigned their respective levels of evidence based on Sackett's classification system as modified by Heinrich [2] (Table 1). Techniques for ET are described hereafter.

The anterior cervical approach, first described by Gagner et al. [3], uses a midline access and permits bilateral dissection of the thyroid. A 5-mm optical trocar is inserted just above the suprasternal notch. Carbondioxide is insufflated with a pressure of $10 \mathrm{mmHg}$. Three additional trocars are used: two 2-mm trocars, and one 5-mm at the superior medial border of the sternocleidomastoid muscle (Fig. 1). Using ultracision, all vital structures are identified and dissected as in a conventional procedure. The piece is extracted in a plastic bag through the superolateral trocar.

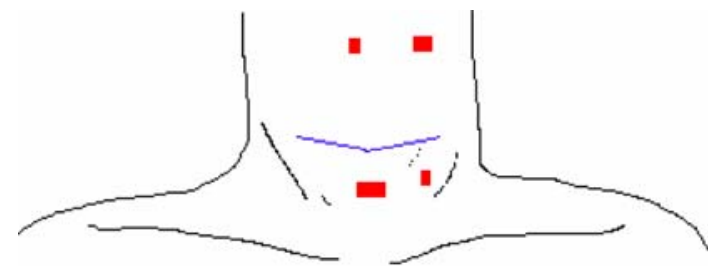

Fig. 1 Anterior direct approach by Gagner

An alternative way to perform ET by anterior approach has been proposed by Cougard et al. (Fig. 2). Starting with a 15-mm median incision above the suprasternal notch, a 5$\mathrm{mm}$ optical trocar is inserted, with $8 \mathrm{mmHg} \mathrm{CO}_{2}$ insufflation. Along the line of a virtual cervicotomy two other trocars are introduced: $3-\mathrm{mm}$ trocar on the side of the operator/lesion, and 5-mm trocar at the other end. A Veress needle is added in the upper midline to improve working space only if necessary [4]. The gland is extracted through the 15-mm median incision, leaving a central neck scar along the line of virtual cervicotomy.

The lateral cervical approach, described by Henry $[1,5,7]$, uses the plane between the carotid sheath laterally and the strap muscles medially. This "back door" route can only be used for unilateral lesions. The procedure is performed via a 10-mm optic port and two 3-mm operating ports, placed on the medial border of the sternocleidomastoid muscle on the side of the lesion. This approach allows direct access to the posterior aspect of the thyroid lobe, without the need for the dissection of the strap muscles. The initial skin incision for the $10-\mathrm{mm}$ port is placed such that in the event of conversion it can be extended medially to result in a symmetric collar incision (Fig. 3). Low-pressure (8 mmHg) insufflation with $\mathrm{CO}_{2}$ maintains the space. Once the lobe is entirely freed, the specimen is extracted through the $12-15-\mathrm{mm}$ incision for division of the isthmus. Granda la Torre et al. [6] describe the use of a balloon dilator for creating the working space instead of blunt dissection.

Another lateral approach has been described by Inabnet et al. [8]. The surgery begins with a $10-15-\mathrm{mm}$ incision at the superior lateral area of the neck. Once sufficient working space is created, three additional trocars (two $3 \mathrm{~mm}$ and one $5 \mathrm{~mm}$ ) are inserted under direct vision (Fig. 4). The specimen is extracted in a retrieval bag through the $1-\mathrm{cm}$ superolateral incision.
Table 1 Sackett's classification of level of evidence

\begin{tabular}{lll}
\hline Level & Type of trial & Criteria for classification \\
\hline I & Large, randomized trials with clear-cut results & Sample size calculation, study end point \\
II & Small, randomized trials & Matched analysis \\
III & Nonrandomized, contemporaneous controls & Noncomparative, prospective \\
IV & Nonrandomized, historical controls & Retrospective analysis, cohort studies \\
V & No control, case series only, opinion of experts & Small series, review articles \\
\hline
\end{tabular}




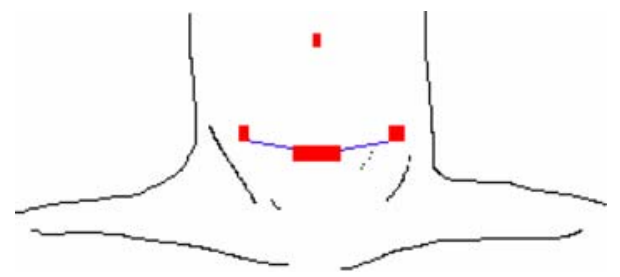

Fig. 2 Anterior direct approach by Cougard

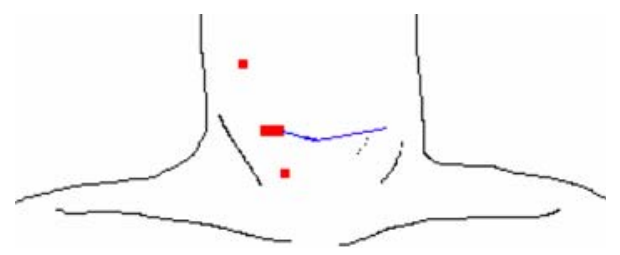

Fig. 3 Lateral direct approach by Henry

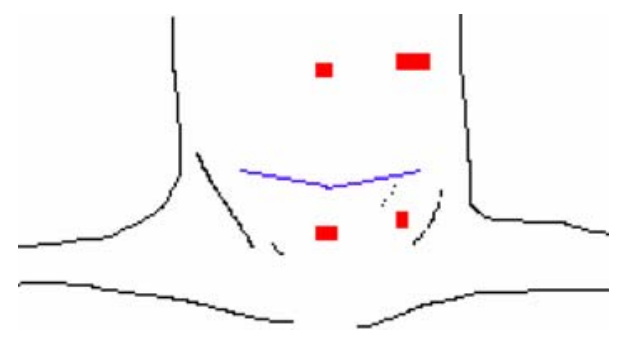

Fig. 4 Lateral direct approach by Inabnet

The chest wall approach is an extra cervical approach favoured for bilateral thyroid dissection. A 30-mm skin incision is made below the inferior border of the clavicle on the side of the lesion, retracting the upper border of the pectoralis major muscle manually. A 12-mm trocar is introduced for a flexible laparoscope. $\mathrm{CO}_{2}$ is insufflated to a pressure of $4 \mathrm{mmHg}$. Alternatively, cutaneous lifting devices are available [9-11]. One 5-mm trocar is inserted inferior to the sternal notch, and one 5-mm trocar below the ipsilateral clavicle (Fig. 5). Dissection of the gland is performed with ultracision. The specimen is retrieved in a bag through the $3-\mathrm{cm}$ subclavicular incision, leaving no scar in the neck.

The breast approach allows bilateral dissection. On both upper circumareolar areas a trocar is inserted (two 10$\mathrm{mm}$ ports, or one $12-\mathrm{mm}$ and one $15-\mathrm{mm}$ port) after blunt dissection with the use of a Rochester clamp and vascular tunneler or Dingmann dissector. The working space is established with $\mathrm{CO}_{2}$ insufflation at a pressure of 4 $6 \mathrm{mmHg}$. The third port $(5 \mathrm{~mm})$ can be inserted $3 \mathrm{~cm}$ below the clavicle on the side of the thyroid mass or parasternal at the level of the nipple or in the axilla as shown in Fig. 6 [12-14]. Ipsilateral strap muscles are split longitudinally to elevate the thyroid and achieve good exposure of the gland. A bilateral axillo-breast approach has been

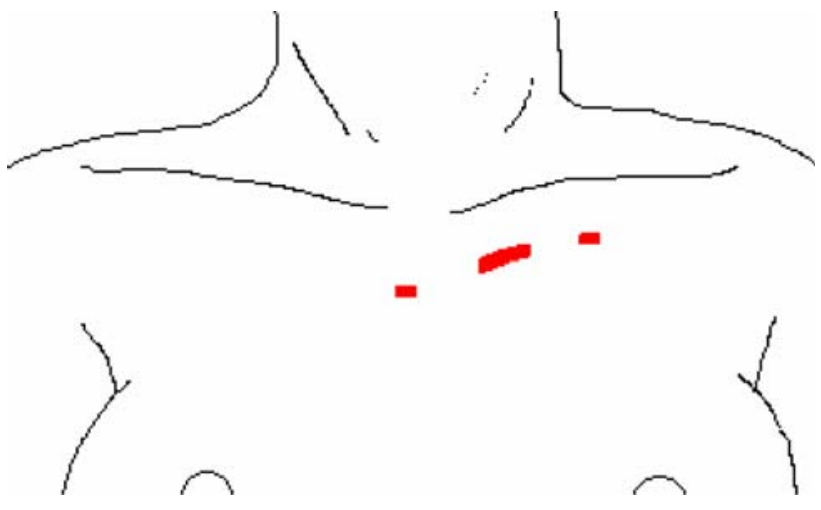

Fig. 5 Indirect chest wall approach
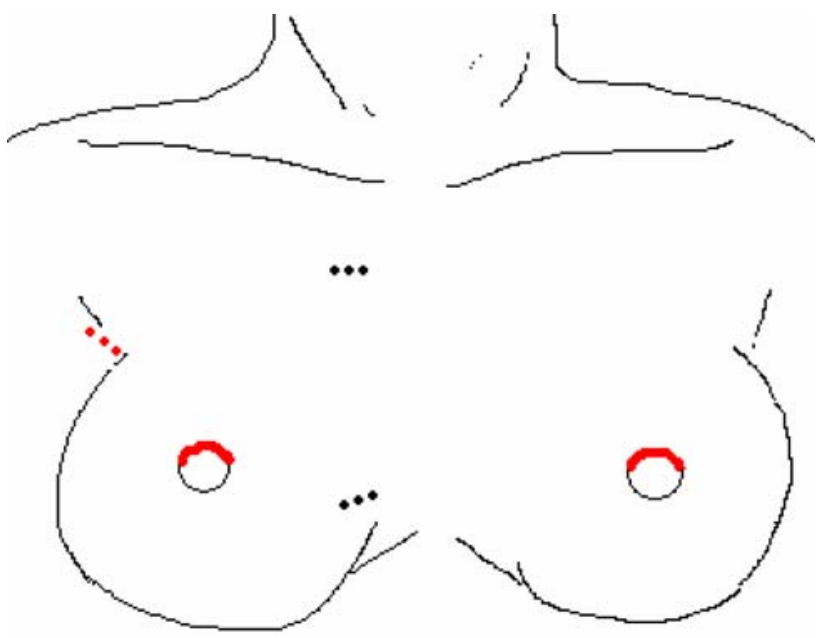

Fig. 6 Indirect breast approach

developed to obtain optimal visualization of both lobes especially for total thyroidectomy in which the third and fourth port are inserted in left and right axilla [15]. The specimen is retrieved through the $12-\mathrm{mm}$ breast ports. Depending on port placement, there are scars parasternal, perimammillary, and/or axillary.

The axillary approach can be used for large thyroid lesion but do not extend contralaterally. The patient is in supine position, and the ipsilateral arm on the side of the lesion placed at a $90^{\circ}$ angle to the axis of the body. Three 5-mm incisions are placed below the anterior axillary line equidistant apart or one $30-\mathrm{mm}$ incision is made for a 12$\mathrm{mm}$ and $5-\mathrm{mm}$ trocar, apart from the third trocar $(5 \mathrm{~mm})$ (Fig. 7). A 5-mm $0^{\circ}$ optical scope or flexible laparoscope with $\mathrm{CO}_{2}$ insufflation at $4-9 \mathrm{mmHg}$ pressure is introduced before starting sharp scissor dissection to dissect an avascular plane between platysma and pectoralis major muscle. A gasless axillary approach is feasible if an external lifting device is applied [16]. Next, the plane between SCM and sternohyoid muscle is developed to elevate the sternothyroid muscle and allow retraction anteriorly, exposing the 


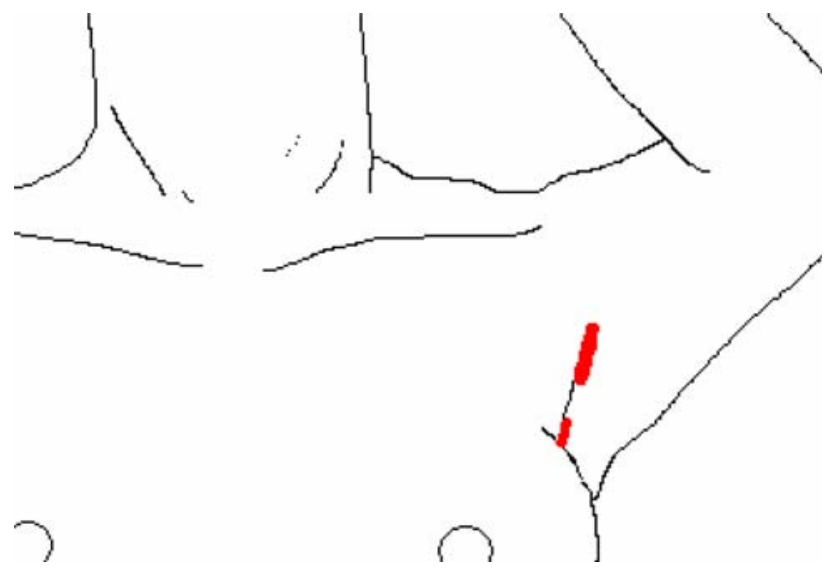

Fig. 7 Indirect axillary approach

ipsilateral thyroid gland. Harmonic scalpel and clips are used for division. A retrieval bag is used for extraction of the gland through the axilla [17-21]. All incisions are hidden in the axillary fossa.

\section{Results}

To our knowledge, data providing Level I evidence (prospective and randomized studies) for ET have not yet been published. Mainly retrospective cohort studies have been published (Table 2). Because of the many possible small differences in approach and poor number of patients or studies published more than once, no meta-analysis can be performed.

\section{Anterior cervical approach}

Gagner et al. [3] presents the results of 18 ET by anterior cervical approach for solitary nodules compared with 18 consecutive classical cervicotomies. Feasibility and safety are confirmed. Aesthetic results are superior and convalescence is reduced compared with classical cervicotomy. Cougard et al. [4] present results of prospectively gathered data on 40 patients demonstrating its feasibility. The use of ultrasonic shears diminished the conversion rate.

\section{Lateral cervical approach}

Henry and Sebag [1], Palazzo et al. [5], and Sebag et al. [7], describe the technique of ET via lateral approach (3 trocars) performed in 38 patients, as developed for parathyroidectomy. The number accounts for approximately $5.1 \%$ of all thyroidectomies performed per year (2004). If frozen-section or definitive histology revealed malignancy that necessitated complete thyroidectomy, it was performed via conventional cervicotomy. Between
Table 2 Published studies on endoscopic thyroidectomy

\begin{tabular}{|c|c|c|c|}
\hline Study & $\mathrm{n}$ & Level & Approach \\
\hline Gagner et al. [3] & 18 & III & Anterior cervical \\
\hline Cougard et al. [4] & 40 & III & Anterior cervical \\
\hline Yeung [22] & 18 & IV & Anterior cervical \\
\hline Casanova [23] & 1 & $\mathrm{~V}$ & Anterior cervical \\
\hline Palazzo et al. [5] & 38 & IV & Lateral cervical \\
\hline Sebag et al. [7] & 38 & IV & Lateral cervical \\
\hline Henry and Sebag [1] & 38 & IV & Lateral cervical \\
\hline Inabnet et al. [8] & 38 & III & Lateral cervical \\
\hline Kitano et al. [9] & 20 & IV & Chest wall \\
\hline Usui et al. [11] & 19 & IV & Chest wall \\
\hline Kim et al. [24] & 35 & IV & Chest wall \\
\hline $\begin{array}{l}\text { Shimizu and Tanaka } \\
{[10]}\end{array}$ & 193 & III-IV & Chest wall \\
\hline Park et al. [13] & 100 & IV & Breast \\
\hline Choe et al. [15] & 135 & III-IV & Breast \\
\hline Ohgami et al. [12] & 5 & IV & Breast \\
\hline Shimazu et al. [14] & 12 & III & Breast \\
\hline Yamamoto et al. [25] & 12 & IV & Breast \\
\hline Yamamoto et al. [26] & 10 & III & Breast \\
\hline Ishii et al. [27] & 5 & IV & Breast \\
\hline Wang et al. [28] & 150 & IV & Breast \\
\hline Ikeda et al. [19] & 15 & II-III & $\begin{array}{l}\text { Axillary and chest } \\
\text { wall }\end{array}$ \\
\hline Takami and Ikeda [29] & 27 & IV-V & Axillary \\
\hline Takami and Ikeda [30] & 36 and 22 & IV & $\begin{array}{l}\text { Axillary and chest } \\
\text { wall }\end{array}$ \\
\hline Ikeda et al. [17] & 1 & $\mathrm{~V}$ & Axillary \\
\hline Duncan et al. [21] & 32 & IV & Axillary \\
\hline Ikeda et al. [18] & 19 & IV & Axillary \\
\hline Ikeda et al. [31] & 20 & III & Axillary \\
\hline Yoon et al. [16] & 30 & IV & Axillary \\
\hline Chantawibul et al. [32] & 20 & IV & Axillary \\
\hline Ikeda et al. [20] & 20 & IV & Axillary \\
\hline
\end{tabular}

2004 and 2007, 112 ETs were performed in our institution. Five procedures were converted and five cases required open completion thyroidectomy for diagnosis of cancer. This experience has lead to a mean operative time of 98 (range, 46-190) minutes. Morbidity rate includes one definitive recurrent nerve palsy and one hematoma, which did not necessitate reoperation.

Inabnet et al. [8] reports three conversions due to insufficient working space in a series of 38 patients.

Chest wall approach

Kitano et al. [9] and Takami and Ikeda [29, 30] present retrospective cohort studies of chest wall (20 and 22 patients respectively) and axillary approach (63 patients). Microcarcinomas and bilateral multinodular goiter are 
included, and according to these authors prophylactic dissection of ipsilateral pre- and para-tracheal nodes seems feasible. Postoperative pain and paraesthesias disappear within 3 months.

Ikeda et al. [19] performed one study that compared conventional, anterior chest, and axillary approaches; each group had 15 patients in which the procedure was selected by turns. Three months postoperatively, the incidence of swallowing discomfort was higher in the open surgery group than in endoscopic surgery group. The axillary approach rendered highest cosmetic results according to patients' questionnaires.

Kim et al. [24] and Shimizu and Tanaka [10] used a gasless retractor system (anterior neck-skin lifting) to minimize possible complications of gas-insufflating surgery. The latter reviews 193 cases and compares them with 20 consecutive conventional cervicotomies. Four of $193(2.1 \%)$ cases of temporal recurrent nerve paralysis, probably the result of thermal injury, are reported. The operative time and amount of bleeding significantly reduced as the surgeon gained experience with the technique.

\section{Breast approach}

Park et al. [13] share their experience in 100 patients operated via breast approach. Six cases were converted to conventional procedures: five because of malignancy on frozen-section, and one because of uncontrolled bleeding/ technical failure. One case of permanent recurrent laryngeal nerve palsy probably caused by thermal injury with ultrasonic scalpel is mentioned, but it is unclear whether all vocal cords were checked postoperatively. Choe et al. [15] presents a 135-patients' retrospective cohort operated by bilateral axillo-breast approach. One procedure was complicated by postoperative infection after primary repair of esophageal injury and one by pneumothorax. Yamamoto et al. [25] reported the feasibility of breast approach for treating patients with Graves' disease by subtotal thyroidectomy. In a small, prospective study [26], 12 conventional thyroidectomies are compared with 10 endoscopic breast procedures. Blood loss was significantly less in the endoscopic group. Convalescence time or any other parameters were not significantly different. The study by Wang et al. [28], on 150 patients treated via the breast approach without any complications occurring and six conversions, could not be retrieved apart from abstract data.

\section{Axillary approach}

Ikeda et al. [19, 20, 31] have published three matched analysis studying the axillary approach. One procedure was complicated by hemorrhage of sternocleidomastoid muscle, which necessitated conversion to open surgery, and one patient had subcutaneous cervical emphysema, which resolved postoperatively. A comparative study of axillary, chest wall, and conventional approach (15 cases per group, selection by turns) revealed excellent cosmetic results in patients treated using the axillary approach, which took the longest operative time (average 175 minutes vs. 145 in chest wall and 84 minutes in open surgery) [19]. Swallowing discomfort was higher in the open surgery group. In comparing $3-\mathrm{cm}$ video-assisted approach, the axillary technique (20 consecutive patients) was significantly more painful [31]. In a retrospective analysis (20 patients per group) operative time for conventional surgery seems significantly shorter, but postoperative paint did not seem to differ between axillary and conventional approach except on the first postoperative day on which the axillary technique is more painful [20].

Duncan et al. [21] published their retrospective results of 32 cases operated for solitary nodules limited to one lobe. Pain and discomfort caused by this approach are noted to subside within 1 week generally, resulting in return to daily activity on day 6.2 after surgery.

Yoon et al. [16] used an external retractor inserted through a 35-mm axillary skin incision and reported a retrospective cohort of 30 patients. Operative time was increased with the size of resected nodule. One minor tracheal injury without air leakage occurred. Patient characteristics and study data are shown in Table 3.

\section{Discussion}

The principal indication for ET remains management of benign thyroid disease. ET using a cervical access is restricted to solitary nodules $<3 \mathrm{~cm}$ in diameter and to thyroid lobes up to $20 \mathrm{ml}$ in volume [1, 3-5, 7, 8, 23]. Larger cysts if preoperatively aspirated may be removed by cervical access. Generally benign nodules $<3 \mathrm{~cm}$ do not require surgery, so only small nodules presenting with follicular cytology or small toxic adenomas are eligible. Therefore, $5-12 \%$ of patients who require surgical intervention for a thyroid nodule may be selected for ET by cervical approach [1, 3, 4]. Small goiters and limited Graves' disease also may be a potential indication for ET, although they generally do not require surgery. Some contraindications are common to all these techniques: large goiters, invasive malignant tumors, previous cervical operations, and history of neck irradiation. Extracervical access permits larger lesions up to $60 \mathrm{~mm}$ in size and enlarged glands (up to $60 \mathrm{ml}$ volume) to be extracted endoscopically and also low-risk carcinomas (to 10$20 \mathrm{~mm}$ in size; younger than aged 50 years, node-negative, intrathyroidal) have been assessed by the extracervical 
Table 3 Patient characteristics and operative data

\begin{tabular}{|c|c|c|c|c|c|c|c|c|c|}
\hline Study & Approach & $\begin{array}{l}\text { Male: } \\
\text { female } \\
\text { ratio }\end{array}$ & $\begin{array}{l}\text { Age } \\
(\mathrm{yr})\end{array}$ & $\begin{array}{l}\text { Nodule } \\
\text { size } \\
(\mathrm{mm})\end{array}$ & $\begin{array}{l}\text { Operating } \\
\text { time } \\
(\min )\end{array}$ & Conversion & $\begin{array}{l}\text { Complication } \\
\text { rate }\end{array}$ & $\begin{array}{l}\text { Nerve } \\
\text { palsy }\end{array}$ & $\begin{array}{l}\text { Discharge } \\
\text { (day) }\end{array}$ \\
\hline Palazzo et al. [5] & $\begin{array}{l}\text { Lateral } \\
\quad \text { cervical }\end{array}$ & $5: 33$ & 45 & 22 & 99 & $5 / 38$ & & 0 & 1 \\
\hline Sebag et al. [7] & $\begin{array}{l}\text { Lateral } \\
\quad \text { cervical }\end{array}$ & & 45 & 19,2 & 102 & $4 / 38$ & & 0 & 1 \\
\hline Inabnet et al. [8] & $\begin{array}{l}\text { Lateral } \\
\quad \text { cervical }\end{array}$ & & & 25 & 190 & $3 / 38$ & & 1 & \\
\hline Gagner et al. [3] & Ant. Cervical & $2: 16$ & 43 & 27 & 220 & $2 / 18$ & 3 hypercapnia & 0 & 1 \\
\hline Cougard et al. [4] & Ant. Cervical & $4: 36$ & 46 & 24 & 89 & $8 / 240 / 16^{\mathrm{c}}$ & & 0 & 1 \\
\hline Yeung et al. $[22,34]$ & Ant. Cervical & & 42 & 25 & 185 & $4 / 18$ & none & & \\
\hline Kitano et al. [9] & Chest wall & $1: 19$ & 44 & 30 & 279 & 0 & 1 emphysema & 1 temp & 4 \\
\hline Ikeda et al. [19] & Chest wall & $1: 14$ & 40 & 40 & 145 & 0 & & 0 & 4 \\
\hline Takami and Ikeda [30] & Chest wall & & 41 & $<54$ & 157 & $1 / 58$ & 1 emphysema & 0 & \\
\hline Usui et al. [11] & Chest wall & & & 35 & 148 & 0 & & 0 & \\
\hline Kim et al. [24] & Chest wall & $3: 32$ & 39 & 30 & 156 & $3 / 35$ & & 1 temp & \\
\hline Shimizu and Tanaka [10] & Chest wall & & & & 120 & 0 & 3 seroma & 4 temp & \\
\hline Park et al. [13] & Breast & 7:93 & 39 & 26 & 100 & & & 1 & \\
\hline Choe et al. [15] & Breast $^{\mathrm{a}}$ & $2: 133$ & 37 & 14 & 175 & & $\begin{array}{c}1 \text { esophageal injury } \\
1 \text { pneumothorax }\end{array}$ & 4 temp & \\
\hline Ohgami et al. [12] & Breast & $0: 5$ & 48 & & 226 & & & & \\
\hline Shimazu et al. [14] & Breast ${ }^{b}$ & $0: 12$ & 34 & 44 & 188 & & & 0 & \\
\hline Shimazu et al. [14] & Breast & $0: 4$ & 41 & 45 & 270 & & & 0 & \\
\hline Yamamoto et al. [25] & Breast & $4: 8$ & 28 & & 260 & & & 1 & \\
\hline Yamamoto et al. [26] & Breast & $0: 10$ & 45 & 38 & & 0 & & 0 & \\
\hline Ishii et al. [27] & Breast & $0: 5$ & 48 & & 226 & & & & \\
\hline Wang et al. [28 & Breast & & & & 80 & $6 / 150$ & none & 0 & 4 \\
\hline Duncan et al. [21] & Axillary & $2: 30$ & 33 & 42 & 139 & 0 & 1 hematoma & 2 temp & 1 \\
\hline Takami and Ikeda [30] & Axillary & & 41 & $<54$ & 172 & $1 / 58$ & & 0 & \\
\hline Ikeda et al. [18] & Axillary & $2: 17$ & 45 & 37 & 212 & $1 / 19$ & & 0 & \\
\hline Ikeda et al. [19] & Axillary & $1: 14$ & 42 & 42 & 175 & 0 & & 0 & 4 \\
\hline Ikeda et al. [31] & Axillary & $1: 19$ & 36 & 42 & 168 & 0 & 1 emphysema & 0 & \\
\hline Ikeda et al. [20] & Axillary & $1: 19$ & 42 & 42 & 168 & 0 & & 0 & 4 \\
\hline Takami and Ikeda [29] & Axillary & & & $<55$ & 172 & $1 / 58$ & 1 emphysema & 0 & \\
\hline Yoon et al. [16] & Axillary & $0: 30$ & 40 & 22 & 127 & & 1 tracheal injury & 0 & 4 \\
\hline Chantawibul et al. [32] & Axillary & & 37 & 30 & 175 & $1 / 45$ & 1 seroma & 1 temp & 3 \\
\hline
\end{tabular}

${ }^{a}$ Bilateral axillo-breast approach

b Axillo-bilateral-breast approach

c Without and with use of ultrasonic shears

approach $[9,15-19,21,25,26,29,30,33]$. Therefore, 34$53 \%$ may be treated by indirect ET [10, 20, 29].

ET takes from 90 minutes for lobectomy by cervical access to 280 minutes for total thyroidectomy by chest wall approach. Adjustments in operative technique and passing the learning curve reduce operative time [18]. Open superior pole division [8], the application of ultracision [4], and limiting indications to maximally $40 \mathrm{~mm}$ unilateral nodes [19] all substantially contribute to shortening of the operative procedure.
The need for custom-engineered skin-lifting devices instead of low-pressure gas insufflation is questionable. Fear of insufflation-related complications, such as hypercapnia, extensive emphysema, and gas embolisms, is not sustained if appropriate precautions are taken: low flow $1 \mathrm{l} /$ min, insufflation pressure $<10 \mathrm{mmHg}$ [35-38].

Morbidity should remain among the main outcome parameters. In extracervical approaches, a minor risk of subcutaneous hemorrhage without any evidence for increasing infection rates is present as a result of the 
extensive dissection [21]. In general, thyroid-specific complications, hypocalcemia, and vocal cord palsy have been poorly evaluated. Preoperative and postoperative laryngoscopy and serum calcium should be performed in a standardized manner to assess morbidity before making any comparison with conventional cervicotomy. Dissection under magnified endoscopic view demonstrating precise anatomic detail may likely enhance patient's safety and contribute to a reduction of $1-3 \%$ incidence of recurrent laryngeal nerve injury $[33,40]$. Until now, we have found no evidence to state that morbidity of ET is at least equal to the conventional equivalent.

The conversion rate varies from $0-13 \%$. Peroperative reasons to convert any ET apart from histology are hemorrhage, difficulty in dissection (due to lack of working space), size of the lesion, thyroiditis, and tracheal injury. Five percent to $11 \%$ of patients operated by direct cervical or indirect breast approach will require a second operation because of definitive malignant histology, despite malignancy being a contraindication for the primary intervention $[1,3,5,7,8,13]$. Reoperation was performed 1 week to 3 months after the primary operation.

Maximization of cosmetic outcome by changing access site is subject to personal opinion. A lateral approach, cervical or axillary, may be cosmetically superior. Patient's satisfaction with the cosmetic result varies from being satisfied to being highly or extremely satisfied. However again, no studies have compared cosmetic outcomes of ET and conventional cervicotomy during longer follow-up.

Whether transection of neck musculature or asymmetry of neck musculature after cutting the omohyoid muscle in extracervical approaches, for example, affects functionality is not clear. Insufficient working space often is followed by conversion and by transection a wider working space is obtained. In axillary and chest wall approach, transection of strap muscles may only be necessary in large tumors. Postoperatively it may cause uncomfortable catching sensation on swallowing by adherence of skin or platysma to sternohyoid muscle; however, this sensation also is experienced by patients after Kocher's cervicotomy.

After extracervical techniques, patients suffer from moderate to severe pain, which gradually subsides within 1 week. Postoperative paresthesias or numbness generally subside within 6 months. After cervical approaches patients are hospitalized for 24 hours. After axillary/chest wall approach it varies from fourth day postoperatively to seventh after breast approach, which may be because of difference in pain. Gagner $[3,33]$ reported a $50 \%$ reduction in convalescence time, which seems of importance. Whether costs of harmonic scalpel, surgical instruments, and longer operative time outweighs the reduction in length of hospital stay (direct approach compared with conventional surgery) and shorter convalescence time is to be investigated.

Controversy remains regarding inclusion of low-risk thyroid carcinoma. Indeed low-risk papillary carcinomas are characteristic of young women searching for a minimal scar. Potential oncologic risks, such as seeding and local recurrence, have not been properly evaluated for endoscopic thyroid surgery $[18,19,39,41]$. Neither has endoscopic neck dissection proven to be feasible rendering exploration in search of enlarged nodes inadequate $[9,10$, $15,30]$. Conversion to assess properly for the presence of lymphadenopathy is advisable.

\section{Conclusions}

The fact that many different endoscopic techniques have been described and that none seem to be universally accepted may be a direct result of technical difficulties and unproven superiority of one technique compared with another. Currently it is not possible to recommend the application of ET based on evidence. However, there exists general agreement that ET is a valid and feasible option for carefully selected patients. Reported complications stress the importance of advanced endoscopic skills and substantial experience in working in two-dimensional field; a must before starting to perform highly advanced endoscopic thyroid surgery. ET should only be offered to carefully selected patients, and therefore, a high volume of patients requiring thyroid surgery is needed. This may only be reached by centralization of thyroid surgery.

Taken together, superiority of endoscopic to conventional thyroidectomy has yet to be demonstrated. The possible advantages of endoscopic thyroid techniques and our patient's desire for the highest cosmetic outcome justify further development of ET in expert hands of endocrine surgeons.

Open Access This article is distributed under the terms of the Creative Commons Attribution Noncommercial License which permits any noncommercial use, distribution, and reproduction in any medium, provided the original author(s) and source are credited.

\section{References}

1. Henry JF, Sebag F (2006) Lateral endoscopic approach for thyroid and parathyroid surgery. Ann Chir 131:51-56

2. Heinrich S, Schafer M, Rousson V et al (2006) Evidence-based treatment of acute pancreatitis: a look at established paradigms. Ann Surg 243:154-168

3. Gagner M, Inabnet BW III, Biertho L (2003) Endoscopic thyroidectomy for solitary nodules. Ann Chir 128:696-701

4. Cougard P, Osmak L, Esquis P et al (2005) Endoscopic thyroidectomy. A preliminary report including 40 patients. Ann Chir 130:81-85 
5. Palazzo FF, Sebag F, Henry JF (2006) Endocrine surgical technique: endoscopic thyroidectomy via the lateral approach. Surg Endosc 20:339-342

6. Granda la Torre LA, Ortega Alvarez F (2007) Tiroidectomia endoscopica: nueva tecnica para el manejo del nodulo benigno de la glandula tiroides. Hospital Nacional Huancayo Essalud. Available at: es.geocities.com, pardal.net

7. Sebag F, Palazzo FF, Harding J et al (2006) Endoscopic lateral approach thyroid obectomy: safe evolution from endoscopic parathyroidectomy. World J Surg 30:802-805

8. Inabnet WB III, Jacob BP, Gagner M (2003) Minimally invasive endoscopic thyroidectomy by a cervical approach. Surg Endosc $17: 1808-1811$

9. Kitano H, Fujimura M, Kinoshita T et al (2002) Endoscopic thyroid resection using cutaneous elevation in lieu of insufflation. Surg Endosc 16:88-91

10. Shimizu K, Tanaka S (2003) Asian perspective on endoscopic thyroidectomy - a review of 193 cases. Asian J Surg 26:92-100

11. Usui Y, Sasaki T, Kimura K et al (2001) Gasless endoscopic thyroid and parathyroid surgery using a new retractor. Surg Today 31:939-941

12. Ohgami M, Ishii S, Arisawa Y et al (2000) Scarless endoscopic thyroidectomy: breast approach for better cosmesis. Surg Laparosc Endosc Percutan Tech 10:1-4

13. Park YL, Han WK, Bae WG (2003) 100 cases of endoscopic thyroidectomy: breast approach. Surg Laparosc Endosc Percutan Tech 13:20-25

14. Shimazu K, Shiba E, Tamaki Y et al (2003) Endoscopic thyroid surgery through the axillo-bilateral-breast approach. Surg Laparosc Endosc Percutan Tech 13:196-201

15. Choe JH, Kim SW, Chung KW et al (2007) Endoscopic thyroidectomy using a new bilateral axillo-breast approach. World J Surg 31:601-606

16. Yoon JH, Park CH, Chung WY (2006) Gasless endoscopic thyroidectomy via an axillary approach: experience of 30 cases. Surg Laparosc Endosc Percutan Tech 16:226-231

17. Ikeda Y, Takami H, Sasaki Y et al (2000) Endoscopic neck surgery by the axillary approach. J Am Coll Surg 191:336-340

18. Ikeda Y, Takami H, Niimi M et al (2002) Endoscopic thyroidectomy and parathyroidectomy by the axillary approach. A preliminary report. Surg Endosc 16:92-95

19. Ikeda Y, Takami H, Sasaki Y et al (2002) Comparative study of thyroidectomies. Endoscopic surgery versus conventional open surgery. Surg Endosc 16:1741-1745

20. Ikeda Y, Takami H, Sasaki Y et al (2003) Clinical benefits in endoscopic thyroidectomy by the axillary approach. J Am Coll Surg 196:189-195

21. Duncan TD, Rashid Q, Speights F et al (2007) Endoscopic transaxillary approach to the thyroid gland: our early experience. Surg Endosc 21:2166-2171

22. Yeung GH (1998) Endoscopic surgery of the neck: a new frontier. Surg Laparosc Endosc 8:227-232
23. Casanova D (2005) Minimally invasive surgery of thyroids and parathyroids. An Sist Sanit Navar 28(Suppl 3):103-108

24. Kim JS, Kim KH, Ahn CH et al (2001) A clinical analysis of gasless endoscopic thyroidectomy. Surg Laparosc Endosc Percutan Tech 11:268-272

25. Yamamoto M, Sasaki A, Asahi H et al (2001) Endoscopic subtotal thyroidectomy for patients with Graves' disease. Surg Today 31:1-4

26. Yamamoto M, Sasaki A, Asahi H et al (2002) Endoscopic versus conventional open thyroid lobectomy for benign thyroid nodules: a prospective study. Surg Laparosc Endosc Percutan Tech $12: 426-429$

27. Ishii S, Ohgami M, Arisaka Y et al (2007) Endoscopic thyroidectomy with precordial approach. Surg Endosc 611

28. Wang CC, Chen J, Hu YZ et al (2004) Endoscopic thyroidectomy with 150 cases. Zhonghua Wai Ke Za Zhi 42:675-677

29. Takami HE, Ikeda Y (2006) Minimally invasive thyroidectomy. Curr Opin Oncol 18:43-47

30. Takami H, Ikeda Y (2003) Total endoscopic thyroidectomy. Asian J Surg 26:82-85

31. Ikeda Y, Takami H, Sasaki Y, Takayama J, Kurihara H (2004) Are there significant benefits of minimally invasive endoscopic thyroidectomy? World J Surg 28:1075-1078

32. Chantawibul S, Lokechareonlarp S, Pokawatana C (2003) Total video endoscopic thyroidectomy by an axillary approach. J Laparoendosc Adv Surg Tech A 13:295-299

33. Naitoh T, Gagner M, Garcia-Ruiz A et al (1998) Endoscopic endocrine surgery in the neck. An initial report of endoscopic subtotal parathyroidectomy. Surg Endosc 12:202-205

34. Yeung GH, Wong HW (2003) Videoscopic thyroidectomy: the uncertain path to practicality. Asian J Surg 26:133-138

35. Rubino F, Pamoukian VN, Zhu JF et al (2000) Endoscopic endocrine neck surgery with carbon dioxide insufflation: the effect on intracranial pressure in a large animal model. Surgery 128:1035-1042

36. Ochiai R, Takeda J, Noguchi J et al (2000) Subcutaneous carbon dioxide insufflation does not cause hypercarbia during endoscopic thyroidectomy. Anesth Analg 90:760-762

37. Gottlieb A, Sprung J, Zhang XM et al (2007) Massive subcutaneous emphysema and severe hypercarbia in a patient during endoscopic transcervical parathyroidectomy using carbon dioxide insufflation. Anesth Analg 84:1154-1156

38. Owaki T, Nakano S, Arimura K et al (2002) The ultrasonic coagulating and cutting system injures nerve function. Endoscopy 34:575-579

39. Miccoli P, Bellantone R, Mourad M, Walz M, Raffaelli M, Berti $P$ (2002) Minimally invasive video-assisted thyroidectomy: multiinstitutional experience. World J Surg 26:972-975

40. de Roy van Zuidewijn DB, Songun I, Kievit J et al (1995) Complications of thyroid surgery. Ann Surg Oncol 2:56-60

41. Miccoli P (2002) Minimally invasive surgery for thyroid and parathyroid diseases. Surg Endosc 16:3-6 